Academic Platform Journal of Engineering and Science

\title{
Sismik Tekstil ile Güçlendirilmiş Düşey Delikli Yığma Tuğla ve Bims Blokların Üç Noktalı Kesme Deneyi
}

\author{
${ }^{* 1}$ Berna İstegün, ${ }^{2}$ Ayşenur Subaşı, ${ }^{* 3}$ Erkan Çelebi \\ ${ }^{1}$ Sakarya Üniversitesi, Fen Bilimleri Enstitüsü, İnşaat Mühendisliği Bölümü, Sakarya, Türkiye, bernaistegun@ sakarya.edu.tr \\ ${ }^{2}$ Sakarya Üniversitesi, Fen Bilimleri Enstitüsü, İnşaat Mühendisliği Bölümü, Sakarya, Türkiye, aysenursubasi@ hotmail.com \\ ${ }^{3}$ Sakarya Üniversitesi, Mühendislik Fakültesi, İnşaat Mühendisliği Bölümü, Sakarya, Türkiye, ecelebi@ sakarya.edu.tr iD
}

$\mathrm{Bu}$ çalışmanın amacı yığma yapı birimlerinin güçlendirme uygulamalarından sonra kırılma durumunu ve kesme kapasitesini ölçmektir. Deneysel araştırmalar yalıtım sıvası ile sismik kumaş kullanarak güçlendirmenin etkilerini göstermek için yürütülmüştür. Güçlendirilmiş sistem, alkali dayanımlı cam elyaf (AR) ve polipropilen liflerden örülmüş çok eksenli sismik tekstil malzemesinden oluşmakta olup; sıvanın malzeme içeriği genleştirilmiş cam kürecik esaslıdır. Üç noktalı kesme deneyleri için tuğla ve bims bloklardan toplam 12 numune üretilerek söz konusu numunelerin bazıları sismik tekstil malzemesi ile güçlendirilmiştir. Güçlendirme işlemi, deney numunesinin tek tarafına $2 \mathrm{~cm}$ kalınlığında olacak şekilde uygulanmıştır. Bütün deneyler Sakarya Üniversitesi'nin yapı mekaniği laboratuvarında gerçekleştirilmiştir. Kuvvet kapasitesi $50 \mathrm{kN}$ olan ve 1.5 $\mathrm{mm} / \mathrm{dk}$ yükleme hızına sahip düşey yük kontrollü silindirin yer değiştirme ölçen mekanik özelliği, kesme gerilmesi etkisindeki yı̆̆ma blok-harç ara yüzeylerinde meydana gelen kayma miktarı ve çatlak davranışları hakkında bilgi edinmek amacıyla kullanılmıştır. Bu deneysel çalışmanın sonuçları, tüm test numuneleri için kuvvet-deplasman ilişkileri açısından karşılaştırmalı olarak verilmiştir. Güçlendirilmemiş numuneler ile gerçekleştirilen deneylerde, eleman-harç ara yüzeyleri boyunca kayma kırılmasının olduğu gözlemlenmiştir. Sismik kumaş ve cam kürecik esaslı yalıtım sıvası uygulanarak güçlendirilen yığma elemanlarda ise dayanımın ve süneklik kapasitesinin önemli ölçüde arttığı sonucuna varılmıştır.

Anahtar Kelimeler: Güçlendirme, sismik kumaş, yığma yapı

\section{Triplet Shear Tests on Brick and Pumice Blocks Strengthened by Seismic Textile}

\author{
${ }^{* 1}$ Berna Istegun, ${ }^{2}$ Aysenur Subasi, ${ }^{* 3}$ Erkan Celebi \\ ${ }^{1}$ Sakarya University, Institue of Science, Department of Civil Engineering, Sakarya, Turkey, bernaistegün@sakarya.edu.tr \\ ${ }^{2}$ Sakarya University, Institue of Science, Department of Civil Engineering, Sakarya, Turkey, aysenursubasi@hotmail.com \\ ${ }^{3}$ Sakarya University, Faculty of Engineering, Department of Civil Engineering, Turkey, ecelebi@ sakarya.edu.tr
}

\begin{abstract}
The goal of this study is to evaluate the shear capacity and the crack pattern of the masonry building units after reinforcing application. Experimental researchs were executed to indicate the effect of strengthening by using the seismic fabric and the relevant specific plaster consisting of expanded glass granular. The reinforcement system is formed both multiaxial textile comprising of alkali resistant glass-polypropylene fibrous and mentioned plaster. For triplet shear tests on perforated bricks and pumice blocks a total of twelve specimens were produced. The plaster having thickness of $2 \mathrm{~cm}$ and reinforcing fabric was applied only unilaterally of the samples. All experiments in this study were performed at Sakarya University's structural mechanics laboratory. The displacement-measuring feature of the vertical load-controlled cylinder with a force capacity of 50 $\mathrm{kN}$ and a loading speed of $1.5 \mathrm{~mm} / \mathrm{min}$ was used to obtain information about the amount of slip and cracking behavior occurring in the block-mortar interface due to shear stress. The results of this experimental study were compared in terms of forcedisplacement relationships for all test samples. It was detected from the final situation of all non-retrofitted specimens had a slip failure along the element-mortar interfaces. It is concluded that the ductility capacity and shear strength increased considerably via seismic fabric and relevant plaster combination.
\end{abstract}

Keywords: Retrofitting, seismic fabric, masonry wall

*Sorumlu Yazar: Sakarya Üniversitesi, Mühendislik Fakültesi, İnşaat Mühendisliği Bölümü, Sakarya, Türkiye, bernaistegun@ sakarya.edu.tr, Tel +90264295 5731

**Bu çalıșma ISHAD2018'de sunulan bildiriden türetilmiștir. 


\section{GÍRIŞ̧}

Son y1llarda yaşanan şiddetli depremlerin neden olduğu ölümlerin ve ölümcül yaralanmaların çoğu; yığma yapıların ana bileşeni olan duvarların hasar görmesi veya çökmesi sonucu meydana gelmiştir. Yığma yapılar; taşıyıcı sistemleri olan duvarlarının, süneklikten yoksun olmaları ve yeterli kesme gerilmesi-kayma dayanımı kapasitesine sahip olmamaları sebebiyle depremlerden önemli ölçüde etkilenmişlerdir. Ancak mevcut yapıların depreme dayanıklılığını, stabilitesini ve süneklik kapasitelerini etkin güçlendirme yöntemleri ile arttırmak mümkündür. Kompozit sismik tekstil malzemelerinin duvar yüzeyine harici olarak uygulanması, bahsi geçen yapıların güçlendirilmesinde sık kullanılan etkili yöntemlerden biridir.

Karlsruhe Teknoloji Enstitüsü laboratuvarında on yıllık bir çalışma sonucu, alkali dirençli cam ve polipropilen liflerden oluşan hibrit çok eksenli sismik kumaş geliştirilerek, yığma duvarlar üzerinde çok sayıda deney gerçekleştirilmiştir [1]. Uygulanan yükler altında, güçlendirilmiş yığma duvar numunesinin davranışını ve oluşan çatlak modellerini daha iyi analiz edebilmek maksadıyla, araştırmacılar tarafından birçok deney düzeneği ve farklı duvar malzemeleri kullanılmıştır [2]. Deneysel programlar, küçük ölçekli duvar numunelerinin yanı sıra; 1:1 ölçeğiyle hazırlanmış gerçek duvar boyutlarındaki numuneleri de içermektedir. Küçük ölçekli testler kapsamında çeşitli kesme deneyi yöntemleri kullanılarak; dayanım parametreleri, kesme gerilmeleri altında duvar derzlerinin davranışı ve oluşan çatlak modelleri incelenmiştir [3].

$\mathrm{Bu}$ çalışmada, kompozit sismik kumaş kullanılarak güçlendirilen ve güçlendirme olmaksızın ele alınan düşey boşluklu tuğla duvar numuneleri ile bims blok duvar numunelerinin statik düşey yükleme altındaki mekanik davranışlarının incelenmesi ve çatlak formlarının belirlenmesi amaçlanmıştır. Yığma birim ve harç ara yüzeyinin kesme performansının belirlenebilmesi amacıyla, söz konusu sismik kumaş, genleştirilmiş cam kürecik esaslı yapıştırma sıvası kullanılarak numune yüzeyine tek taraflı olarak uygulanmıştır. Sıva kalınlığı $2 \mathrm{~cm}$ olarak dikkate alınmıştır. Referans olarak değerlendirilen güçlendirilmemiş numuneler uygulanan üç noktalı kesme deneyleri ile ayrıca incelenerek, elde edilen deney sonuçları kuvvet-yer değiştirme ilişkileri ve kayma dayanımı parametreleri karşılaştırmalı olarak verilmiştir.

\section{MATERYAL VE METOD}

Sakarya Üniversitesi'nin yapı malzemesi laboratuvarında yükleme hızı $1.5 \mathrm{~mm} / \mathrm{dk}$ olan basma-çekme test cihazı kullanılarak yürütülen deneylerde; üçlü blok numuneler düşey yüke tabi tutulup, tuğla ve bims duvar-harç ara yüzeyinden kaymaya zorlanmıştır. Eğilme momentinin etkisini azaltmak ve uygulanan yükü düzgün bir şekilde aktarabilmek amacıyla, üçlü numunenin orta tuğlası üzerine çelik levha yerleştirilmiştir. Her iki uçtaki tuğla/bims elemanlar ise rijit iki L profil tarafından desteklenerek ankastre mesnet koşullarının oluşturulması sağlanmıştır. Bims duvar durumundaki mesnet koşullarının tuğla duvar durumundaki mesnet koşullarına eşdeğer olabilmesi için bu iki L profil gijon demirlerle sıkıştırılıp birbirlerine sabitlenmiştir. Bims bloklar ile oluşturulan numunelerin genişliği cihaz açıklığından büyük olduğu için ilgili numuneler test cihazına tuğla elemanların yerleştirildiği doğrultunun aksi doğrultuda konuşlandırılmıştır. Bunun sonucu olarak düzeneğin havada kalan kısımları $10 \times 10$ cm'lik ağaç ayaklar ve teleskopik direkler ile desteklenmiştir. Deneysel çalışmanın sonuçları, $50 \mathrm{kN}$ düşey kuvvet kapasitesine sahip yük silindirine entegre edilmiş bir yer değiştirme sensörü tarafından kaydedilmiştir.

\subsection{Test Numunelerinin Ve Deney Düzeneklerinin Özellikleri}

Test numunelerinde kullanılan düşey delikli tuğla ve bims blok Şekil 1'de gösterilmiştir.
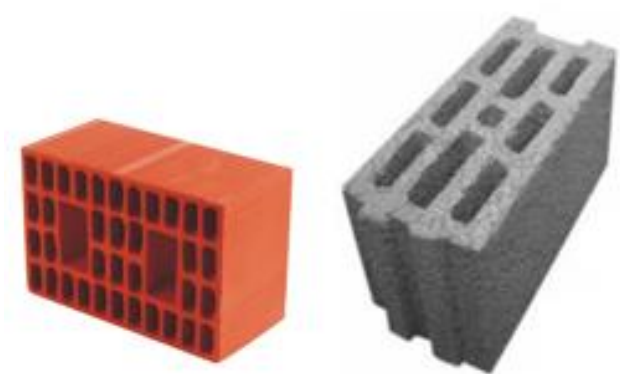

Şekil 1. Test numunelerinde kullanılan düşey delikli tuğla ve bims blok

Tuğla ve bims bloğa ait teknik özellikler ise Tablo 1'de verilmiştir. Bahsi geçen yığma bloklara ait basınç dayanımı değerleri tuğla için 6-15 $\mathrm{MPa}$, bims için 1.2-2.5 $\mathrm{MPa}$ değerleri arasında değişmekte olup, tabloda ifade edilen dayanım verileri deneysel çalışmalardan elde edilen ortalama değerlerdir.

Tablo 1. Tuğla ve Bims Özellikleri

\begin{tabular}{|c|c|c|c|}
\hline & BIRIM & TUĞLA & BİMS \\
\hline Ebat & $\mathrm{cm}$ & $19 \times 29 \times 13.5$ & $19 \times 39 \times 18.5$ \\
\hline Sarfiyat & $\operatorname{adet} / \mathrm{m}^{2}$ & $22-35$ & $12.5-13$ \\
\hline Basınç Dayanımı & $\mathrm{N} / \mathrm{mm}^{2}$ & 10 & 1.5 \\
\hline Isıl Direnç & $\mathrm{W} / \mathrm{mK}$ & 0.32 & 0.22 \\
\hline Yangına Dayanım & - & A1 & A1 \\
\hline $\begin{array}{l}\text { Tolerans } \\
\text { Kategorisi }\end{array}$ & - & $\mathrm{T} 1$ & D1 \\
\hline $\begin{array}{l}\text { Brüt Kuru Birim } \\
\text { Hacim Kütlesi }\end{array}$ & $\mathrm{kN} / \mathrm{m}^{3}$ & 6.86 & 5.39 \\
\hline $\begin{array}{l}\text { Net Kuru Birim } \\
\text { Hacim Kütlesi }\end{array}$ & $\mathrm{kN} / \mathrm{m}^{3}$ & 17.65 & 7.35 \\
\hline
\end{tabular}

Üretilen 12 adet numune Şekil 2'de gösterilen üçerli bloklardan oluşturulmuştur. İlgili numunelerin genleştirilmiş cam kürecik esaslı yapıştırma sıvası kullanılmak suretiyle 6 
tanesi güçlendirilmiş olup, kalan üçer adet numune referans olarak ele alınmıştır.
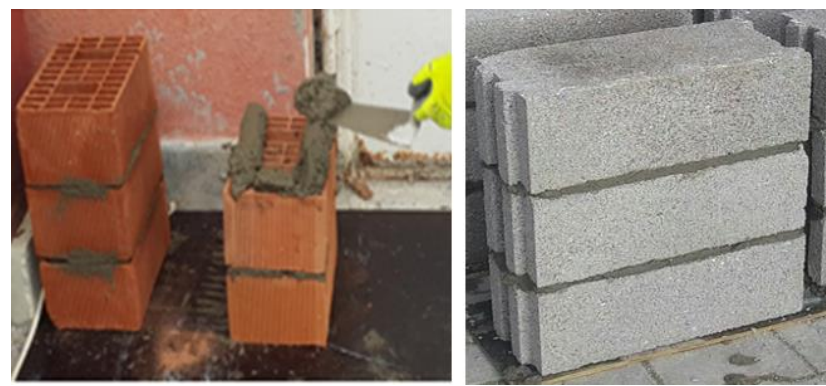

Şekil 2. Deneylerde kullanılan üçlü test numuneleri

Söz konusu güçlendirme işlemi, Şekil 3 'te gösterildiği üzere alkali dirençli cam elyaf ve polipropilen liflerden oluşan çok eksenli hibrit sismik tekstil malzemesi ve özel yapıştırma sıvasının bir kombinasyonudur. İlgili kompozit kumaşa ait düşey, yatay ve diyagonal doğrultuda $\left(60^{\circ}\right)$ çekme mukavemetinin ortalama değerleri ise sırasıyla $53.6 \mathrm{~N} / \mathrm{mm}$, $42.0 \mathrm{~N} / \mathrm{mm}$ ve $14.4 \mathrm{~N} / \mathrm{mm}$ 'dir.

Üçlü numunelerin oluşturulması amacıyla kullanılan derz malzemesi çimento harcı olup, çimento/kum hacimsel oranı 1/4'tür. Güçlendirme işlemi için öncelikle üçlü numune yüzeyine ince bir tabaka olacak şekilde genleştirilmiş cam kürecik esaslı sıva uygulanmış daha sonra ise sismik kumaş yapıştırılarak bu kumaşın üzeri tekrar ilgili özel sıva ile sıvanmıştır. $\mathrm{Bu}$ işlem tüm numuneler için benzer şekilde olup numunelerin tek yüzeyi güçlendirilmiş ve sıva kalınlığı $2 \mathrm{~cm}$ olacak şekilde uygulama yapılmıştır.

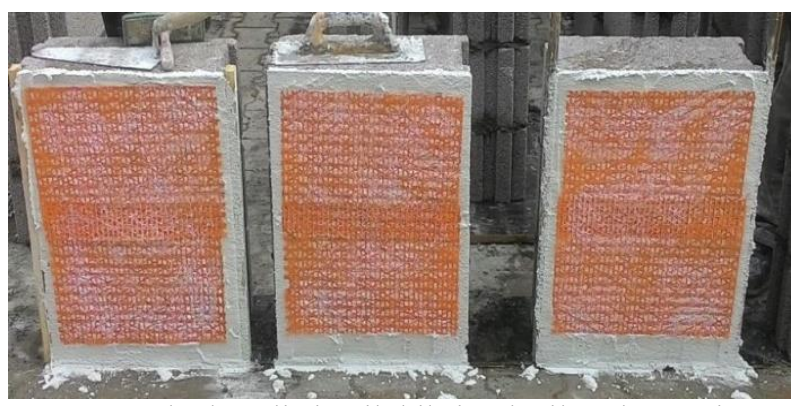

Şekil 3. Çok eksenli sismik hibrit tekstil malzemesi

Deneysel çalışmanın amacı, kompozit sismik kumaş ile güçlendirilmiş düşey boşluklu tuğla duvar elemanlarının kesme kuvveti altında mekanik karakteristikleri ve çatlak formlarının belirlenmesi ve elde edilen verilerin güçlendirilmemiş referans numuneler ile karşılaştırmalı olarak incelenmesidir.

Üç noktalı kesme deneyinin şematik gösterimi Şekil 4'te verilmiş olup, düşey delikli tuğla deneylerinde kullanılan $\mathrm{L}$ profil ve levha kalınlıklar1 $t_{\mathrm{s} 1}=30 \mathrm{~mm}, t_{\mathrm{s} 2}=12 \mathrm{~mm}, \mathrm{t}_{\mathrm{s} 3}=12$ mm'dir. Bims blok deneylerinde kullanılan levha kalınlıkları ise $\mathrm{t}_{\mathrm{s} 1}=35 \mathrm{~mm}, \mathrm{t}_{\mathrm{s} 2}=20 \mathrm{~mm}, \mathrm{t}_{\mathrm{s} 3}=15 \mathrm{~mm}$ 'dir.

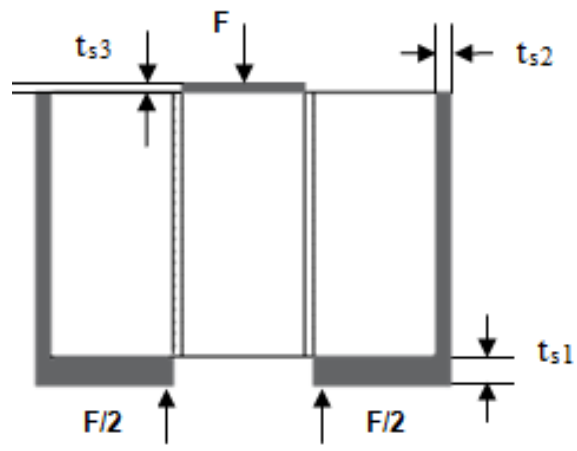

Şekil 4. Deney düzeneği

Çalışma kapsamında yürütülen 12 adet deney, Şekil 5'te verilen basma-çekme test cihazında gerçekleştirilmiştir.

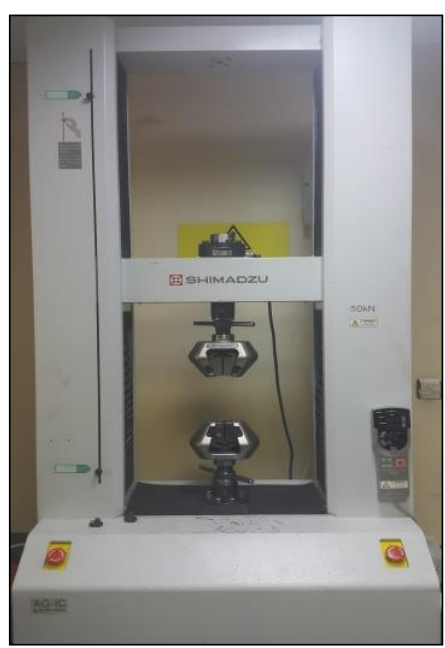

Şekil 5. Basma-çekme test cihazı

\subsection{Deney Programı Ve Sayısal Bulgular}

Oluşturulan her bir üçlü deney grubu için bir isimlendirme yapılmış olup, Tablo 2'de bu kodlara yer verilmiştir.

Tablo 2. Duvar Numunelerinin Kodları

\begin{tabular}{|c|c|c|c|}
\hline $\begin{array}{l}\text { Duvar } \\
\text { Kodu }\end{array}$ & $\begin{array}{l}\text { Güçlendirme } \\
\text { Durumu }\end{array}$ & $\begin{array}{c}\text { Duvar } \\
\text { Tipi }\end{array}$ & Siva Tipi \\
\hline D1R00 & Referans & Tuğla & Sivasız \\
\hline D3R00 & Referans & Bims & Sivasiz \\
\hline D1G03 & Var & Tuğla & $\begin{array}{l}\text { Cam kürecik esaslı } \\
\text { siva }\end{array}$ \\
\hline D31G03 & Var & Bims & $\begin{array}{l}\text { Cam kürecik esaslı } \\
\text { siva }\end{array}$ \\
\hline
\end{tabular}

Referans olarak değerlendirilen güçlendirilmemiş tuğla numuneler D1R00 olarak isimlendirilmiştir. Bu gruba ait üç adet numune üzerinde gerçekleştirilen deneylerde, kuvvetyer değiştirme eğrileri elde edilmiştir. D1R00 grubuna ait 1. numunenin deney öncesi ve kesme kuvvetine maruz bırakıldıktan sonraki durumu Şekil 6'da gösterilmiştir. 

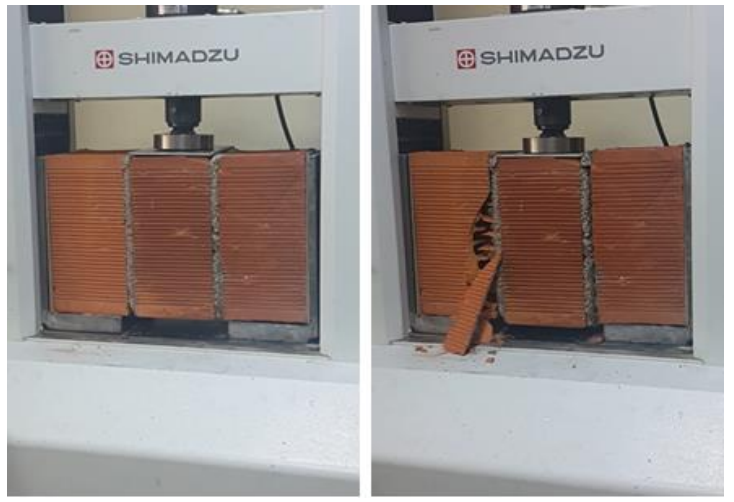

Şekil 6. D1R00 grubuna ait 1. numunenin deney öncesi ve sonrasındaki durumu

Deney yaklaşık 9 dakika sürmüş ve derzlerde başlayan kırılma, tuğla duvar elemanlarının da çatlayarak kırılmasına sebep olmuştur. Taşınabilen maksimum kesme kuvveti 12 $\mathrm{kN}$ mertebelerine ulaştıktan sonra numune yatay yük taşıma kapasitesini büyük oranda yitirmiştir. Numune yüzeyinde çok fazla kılcal çatlak gözlenmemiş, ani kırılmalar ile sistem göçme mekanizmasına ulaşmıştır.

Her gruba ait üç numune olması sebebiyle D1R00-1, D1R002 ve D1R00-3 şeklinde isimlendirme yapılmıştır. D1R00-1 numunesi için üç noktalı kesme deneyi altında elde edilen maksimum kuvvet $12200 \mathrm{~N}$ olmuştur. Bu sete ait 2. ve 3 . numuneler de benzer şekilde test edilmiş ve çatlak formları Şekil 7'de gösterilmiştir.
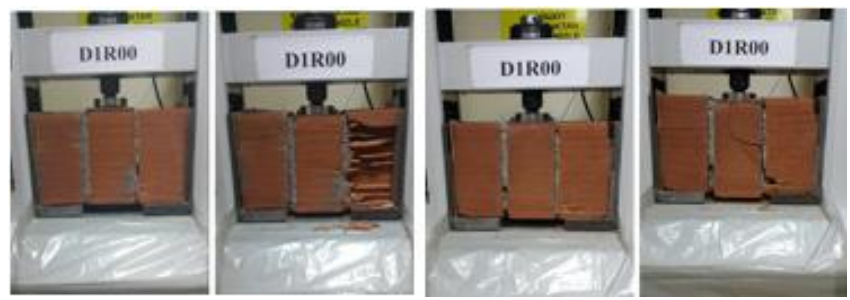

Şekil 7. D1R00 grubuna ait 2. ve 3. numunelerin deney öncesi ve sonrasındaki durumu

Kesme kuvvetine maruz birakılan ikinci numunede sağ tarafta bulunan tuğla tamamen parçalanmış ve ortadaki tuğla derz düzleminden kayarak gevrek bir göçme mekanizması oluşmuştur. D1R00 deney setine ait son numunede ise ilk çatlaklar sağ tarafta bulunan tuğlanın alt kısmında meydana gelmiştir. Kesme kuvveti maksimum değeri olan $15 \mathrm{kN}$ seviyelerine ulaştıktan sonra numunenin yatay yük taşıma kapasitesinde ani bir düşüş gözlenmiş ve ortadaki tuğlada oluşan çatlaklar oldukça genişlemiştir. Kullanılan tuğlaların 135 mm olması gereken kenarları, üretim kaynaklı kusurdan ötürü daha küçük olduğundan; numune $\mathrm{L}$ profillere yerleştirilirken, derz düzlemi L profilin bittiği noktaya denk gelmemiş ve mesnede oturan sağ tuğlanın derze yakın köşesinde gerilme yığılmaları meydana geldiğinden kırılmalar gözlenmiştir. D1R00-2 ve D1R00-3 numuneleri için ise maksimum kesme kuvveti değerleri $12920 \mathrm{~N}$ ve 15316 N olarak ölçülmüştür. Kuvvet-yer değiştirme ilişkileri Şekil 8'de karşılaştırmalı olarak sunulmuştur.

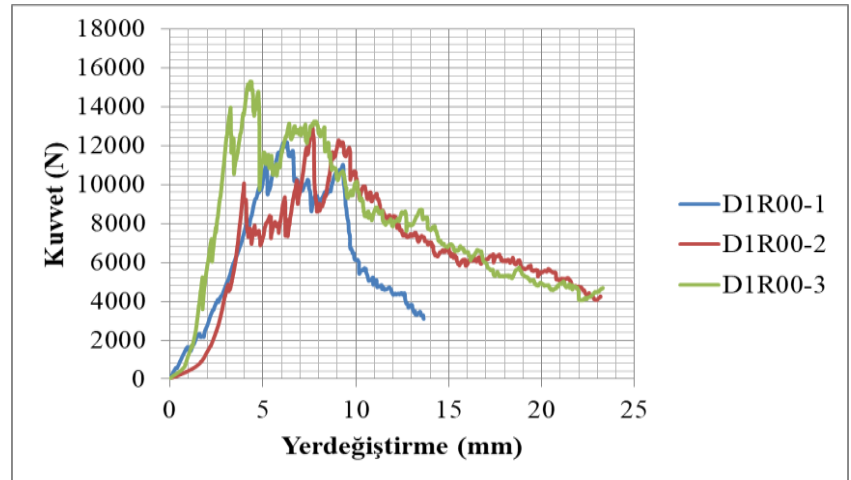

Şekil 8. D1R00 numunelerinin kuvvet-yerdeğiştirme ilişkilerinin karşılaştırılması

D1R00-1 numunesi için $f_{v}$ kayma gerilmesi EN 1052-3'e [4] göre Denklem 1'de verildiği gibi hesaplanmıştır. Burada $F_{\max }$ maksimum kesme kuvveti değerini, A ise tuğla duvarharç ara yüzey alanını ifade etmektedir.

$f_{v}=F_{\text {max }} / 2 A$

$f_{v}=12200 /(2 \times 190 \times 290)=0.111 \mathrm{MPa}$

D1R00-2 ve D1R00-3 numuneleri için de $f_{v}$ kayma gerilmesi değerleri sirasiyla 0.117 ve $0.139 \mathrm{MPa}$ olarak hesaplanmıştır.

Güçlendirilmemiş bims numunelerin isimlendirilmesinde ise D3R00 kodu kullanılmıştır. Bu gruba ait üç adet numune üzerinde gerçekleştirilen deneylerde, kuvvet-yer değiştirme eğrileri elde edilmiştir. D3R00 grubuna ait 1. numunenin yükleme öncesi ve kesme kuvvetine maruz bırakıldıktan sonraki durumları Şekil 9'da verilmiştir.
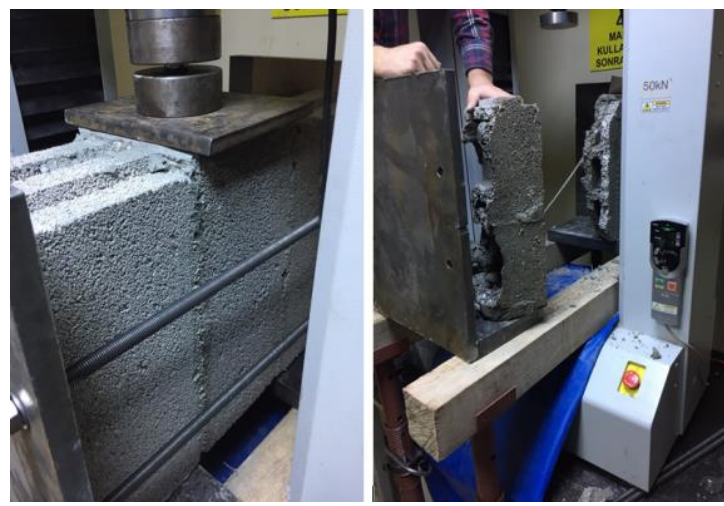

Şekil 9. D3R00 grubuna ait 1. numunenin deney öncesi ve sonrasındaki durumu

Güçlendirme olmaksızın dikkate alınan bims grubuna ait numunelerde; D3R00-1 için üç noktalı kesme deneyi altında 31073 N olarak belirlenen maksimum kuvvet, D3R00-2 için $23607 \mathrm{~N}$ ve D3R00-3 için 31384 N olarak elde edilmiştir. Bu sete ait 2. ve 3. numunelerin çatlak formları da Şekil 10'da gösterilmiştir. 

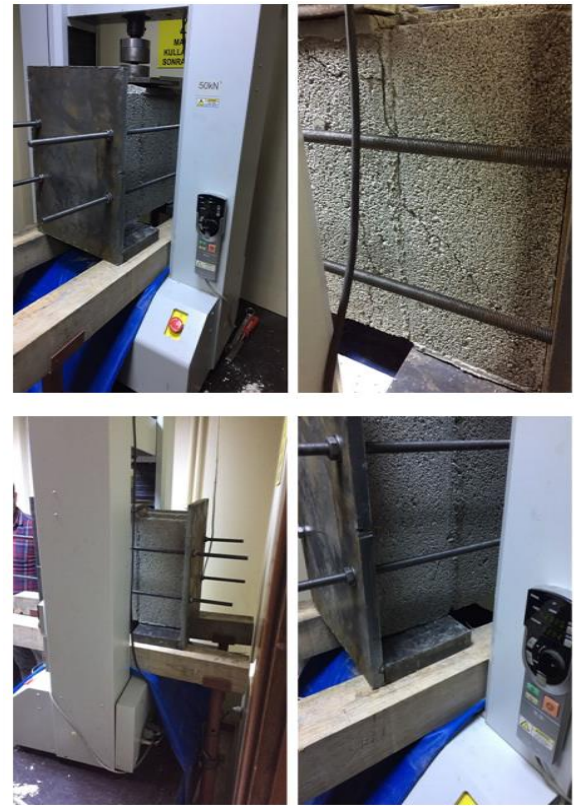

Şekil 10. D3R00 grubuna ait 2. ve 3. numunelerin deney öncesi ve sonrasındaki durumu

Referans olarak değerlendirilen bims grubu numunelerinin maksimum kesme kuvvetlerine karşıllı gelen $f_{v}$ kayma gerilmesi değerleri ise sirası ile $0.210 \mathrm{MPa}, 0.159 \mathrm{MPa}$ ve $0.212 \mathrm{MPa}$ olarak hesaplanmıştır. Kuvvet-yerdeğiştirme ilişkileri Şekil 11'de karşılaştırmalı olarak sunulmuştur.

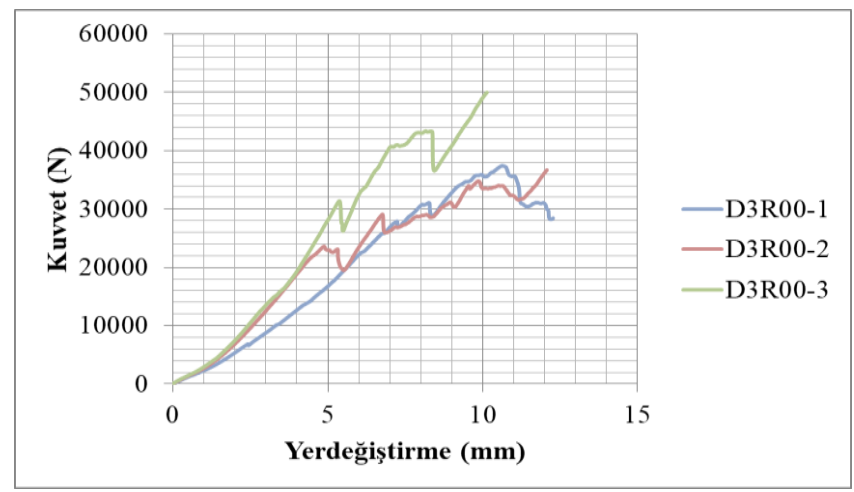

Şekil 11. D3R00 numunelerinin kuvvet-yerdeğiştirme ilişkilerinin karşılaştırılması

Deneysel çalışmanın ikinci aşamasında; genleştirilmiş cam kürecik esaslı yapıştırma sıvası aracılığıyla numune yüzeyine tek taraflı uygulanan çok eksenli sismik tekstil malzemesinin, kesme kapasitesine etkisi incelenmiştir. Burada, $2 \mathrm{~cm}$ kalınlığındaki güçlendirme tabakasının tek taraflı uygulanması ile oluşturulan tuğla ve bims blok numuneleri sirasiyla D1G03 ve D31G03 olarak adlandırılmıştır. Düşey yük etkisinde incelenen D1G03 grubuna ait ilk numunenin deney öncesi görünümü ve meydana gelen çatlak formu Şekil 12'deki gibidir.

$\mathrm{Bu}$ deneyde ilk gözle görülebilen çatlak, yük $20000 \mathrm{~N}$ mertebelerindeyken sağ alt derz başlangıç noktasında oluşmuştur. Maksimum kesme kuvveti değeri olan 23032 N'a ulaşıldıktan sonra yükte ani bir düşüş meydana gelmiş ve sağ alttaki çatlak yukarıya doğru genişleyerek ilerlerken sol alt derz düzleminde de kılcal çatlaklar görülmeye başlanmıştır. Deprem kumaşının bağlayıcı sıva ve dolayısıyla tuğla bloklar ile iyi aderans göstermesi ve sismik tekstilin parçalanmayarak numuneyi artan yük etkisinde tutması, kayma davranışının aniden (gevrek) olmasını engellemiş, enerji ön yüzeyde görülen k1lcal çatlaklarla sünek bir şekilde tüketilmiştir. D1G03-1 kodlu numune için maksimum kesme kuvvetine karşılık gelen kayma gerilmesi değeri ise 0.209 MPa olarak hesaplanmıştır. Geriye kalan güçlendirilmiş deney numuneleri de test edilerek, kırılma biçimleri Şekil 13'te gösterilmiştir.
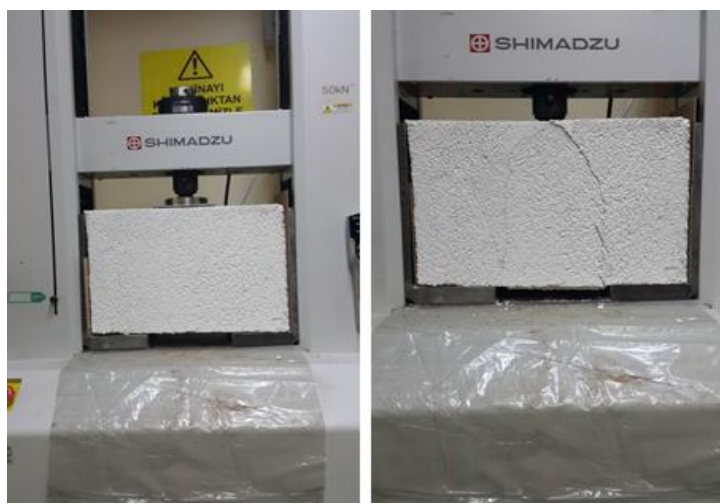

Şekil 12. D1G03 setine ait ilk numunenin deney öncesi ve sonrasindaki durumu
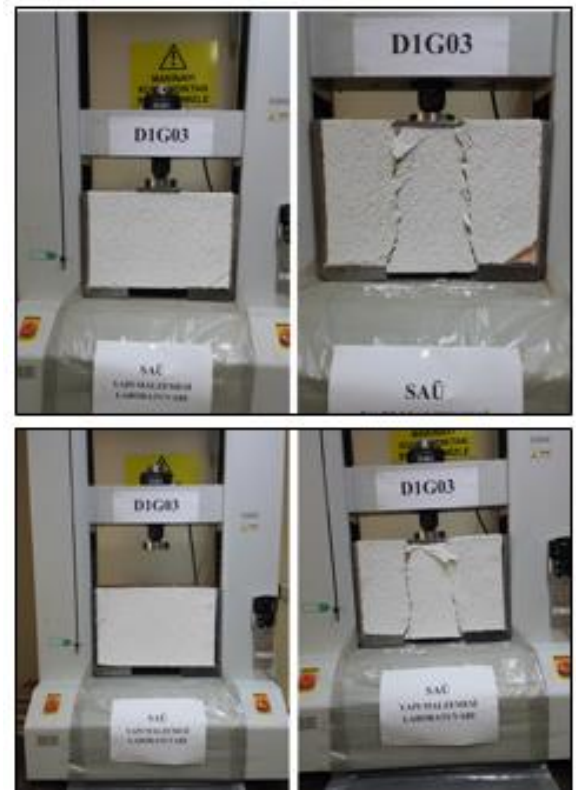

Şekil 13. D1G03-2 ve D1G03-3 numunelerinin deney öncesi ve sonrasındaki durumu

D1G03-2 numunesi maksimum 24548 N kesme kuvvetini taşıyabilmiş, bu yük değerine ulaştıktan sonra ön yüzeyde diyagonal ve düşey çatlaklar meydana gelmiştir. Kuvvette ani bir düşüş meydana gelmemiş, numune kalıcı deplasmanlar yaparak ve oluşan çatlakların genişlemesi suretiyle göçme mekanizmasına ulaşmıştır. Deney setine ait son numunenin mekanik davranışı da oluşan çatlak formları bakımından aynı sete ait diğer numuneler ile benzerlik 
göstermektedir. Son numune için ölçülen maksimum kesme kuvveti değeri ise yaklaşık 29400 N'dur.

Söz konusu kuvvet değerlerine karşılık gelen $f_{v}$ kayma gerilmesi değerleri sırası ile $0.223 \mathrm{MPa}$ ve $0.267 \mathrm{MPa}$ olarak belirlenmiştir. Kuvvet-yerdeğiştirme ilişkileri Şekil 14'te karşılaştırılmalı olarak verilmiştir.

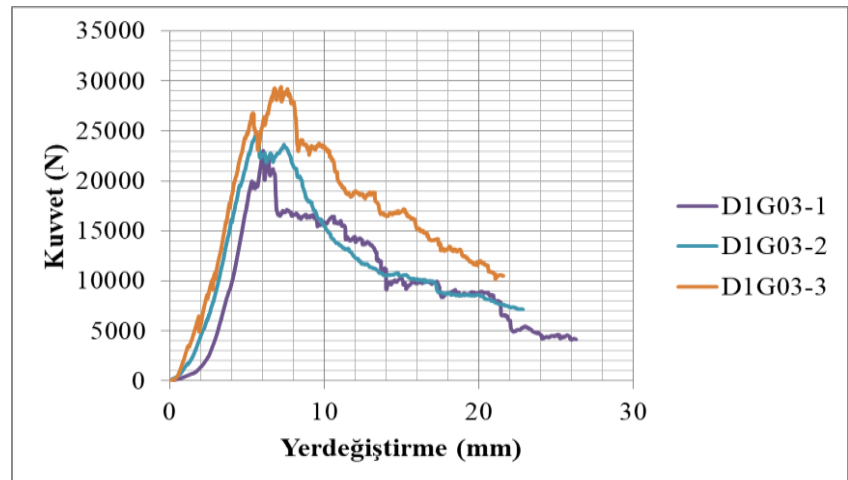

Şekil 14. D1G03 numunelerinin kuvvet-yerdeğiştirme ilişkilerinin karşılaştırılması

Güçlendirilmiş bims numuneleri olan D31G03 numune grubuna ait 1 . numunede deney sonrası meydana gelen çatlak formları Şekil 15 'te gösterilmiştir.
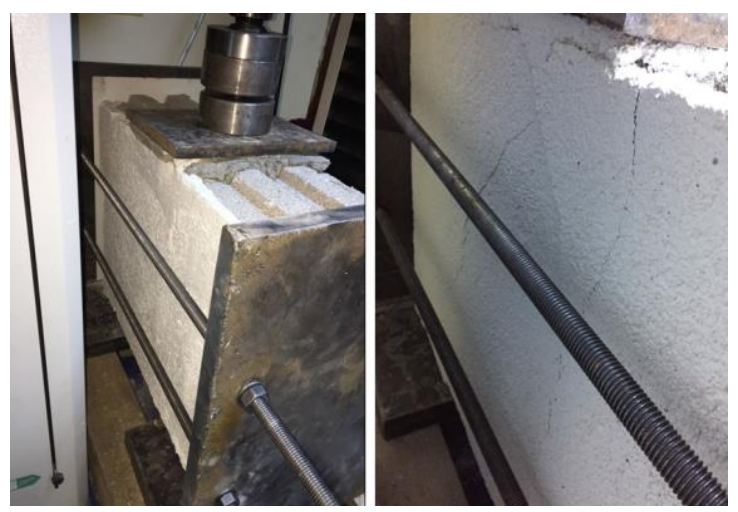

Şekil 15. D31G03 setine ait ilk numunenin deney öncesi ve sonrasındaki durumu

D31G03-1 kodlu numune için maksimum kesme kuvvetinin değeri 35829 N olarak ölçülmüş ve buna karşılık gelen kayma gerilmesi değeri $0.242 \mathrm{MPa}$ olarak hesaplanmıştır. Diğer güçlendirilmiş deney numuneleri de test edilerek, kırılma biçimleri Şekil 16'da gösterilmiştir.

D31G03-2 ve D31G03-3 numuneleri için de aynı yol izlenerek çatlak biçimleri, maksimum kesme kuvveti ve dayanım parametreleri saptanmıştır.

D31G03-2 için $33164 \mathrm{~N}$ ve D31G03-3 için $40040 \mathrm{~N}$ olan kesme kuvvetlerine karşılık gelen $f_{v}$ değerleri sırası ile 0.224 $\mathrm{MPa}$ ve $0.270 \mathrm{MPa}$ olarak hesaplanmıştır. Kuvvetyerdeğiştirme ilişkileri Şekil 17'de karşılaştırmalı olarak verilmiştir.
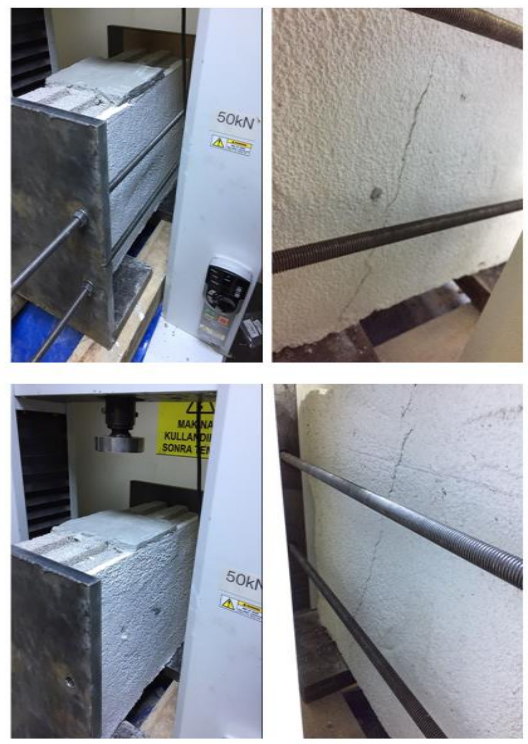

Şekil 16. D31G03-2 ve D31G03-3 numunelerinin deney öncesi ve sonrasındaki durumu

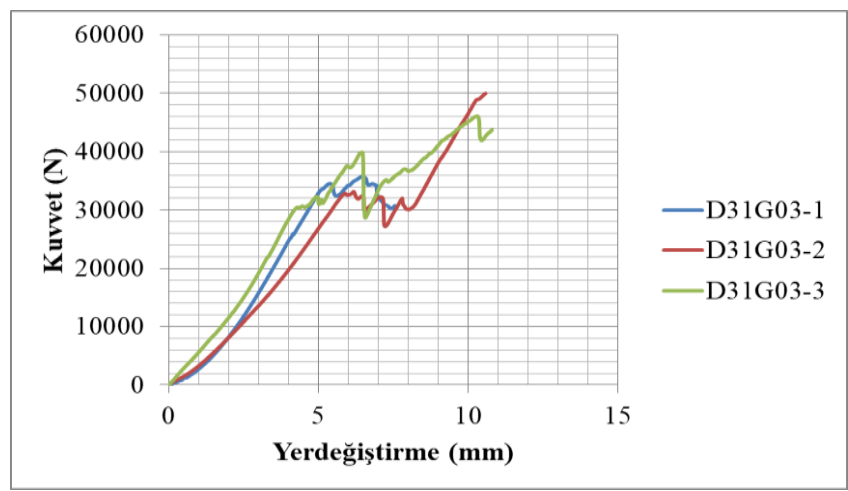

Şekil 17. D31G03 numunelerinin kuvvet-yerdeğiştirme ilişkilerinin karşılaştırılması

\section{SONUÇLAR}

Bütün numunelere ait maksimum kesme kuvvetleri ve kayma gerilmeleri Tablo 3 'te ifade edilmiştir.

Tablo 3. Numunelerin Maksimum Kesme Kuvveti ve Kayma Gerilmesi Değerleri

\begin{tabular}{lll}
\hline \hline Duvar Kodu & $\mathbf{F}_{\max }(\mathbf{N})$ & $\mathbf{f}_{\mathbf{v}}(\mathbf{M P a})$ \\
\hline D1R00-1 & 12200 & 0.111 \\
D1R00-2 & 12920 & 0.117 \\
D1R00-3 & 15316 & 0.139 \\
D3R00-1 & 31073 & 0.210 \\
D3R00-2 & 23607 & 0.159 \\
D3R00-3 & 31384 & 0.212 \\
D1G03-1 & 23032 & 0.209 \\
D1G03-2 & 24548 & 0.223 \\
D1G03-3 & 29400 & 0.267 \\
D31G03-1 & 35829 & 0.242 \\
D31G03-2 & 33164 & 0.224 \\
D31G03-3 & 40040 & 0.270 \\
\hline \hline
\end{tabular}


Tüm numunelerin kayma gerilmeleri elde edildikten sonra numune gruplarını karşılaştırabilmek için ortalama kayma dayanımları ve karakteristik kayma dayanımları hesaplanmıştır.

$$
\begin{aligned}
& f v_{m}=\frac{\sum_{i=1}^{n} f v_{n}}{n} \\
& f v_{k}=0.8 \times f v_{m}
\end{aligned}
$$

$f v_{m}$ : Ortalama kayma dayanımı

$f v_{k}:$ Karakteristik kayma dayanımı

Ortalama ve karakteristik dayanımlar Denklem 2 ve 3 'te belirtilen formüller ile hesaplanarak Tablo 4'te gösterilmiştir.

Tablo 4. Ortalama ve Karakteristik Kayma Dayanımları

\begin{tabular}{ccc}
\hline \hline $\begin{array}{c}\text { Duvar } \\
\text { Kodu }\end{array}$ & $\mathbf{f}_{\mathrm{vm}}(\mathbf{M P a})$ & $\mathbf{f}_{\mathrm{vk}}(\mathbf{M P a})$ \\
\hline D1R00 & 0.122 & 0.098 \\
D3R00 & 0.194 & 0.155 \\
D1G03 & 0.233 & 0.186 \\
D31G03 & 0.245 & 0.196 \\
\hline \hline
\end{tabular}

Tüm numunelerin kuvvet-deplasman ilişkilerinin karşılaştırılması Şekil 18'de verilmiştir.

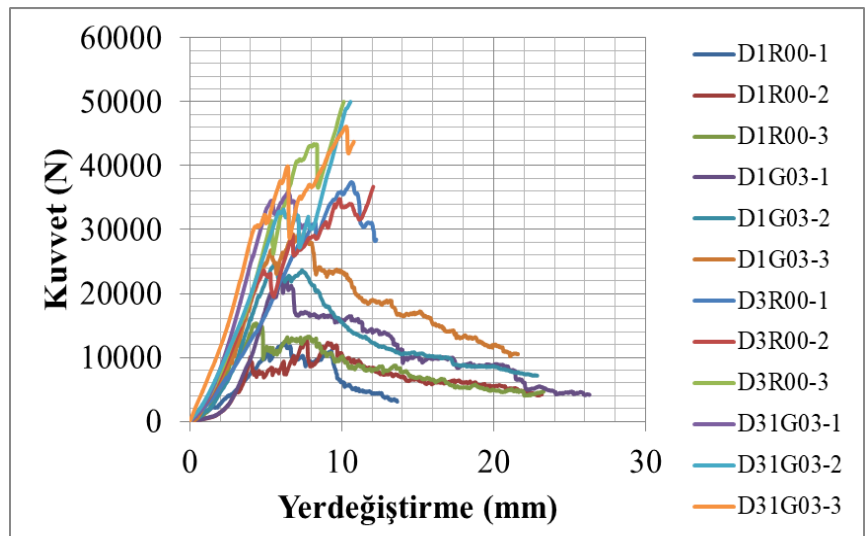

Şekil 18. Tüm numunelerin kuvvet-yerdeğiştirme ilişkilerinin karşılaştırılması

\section{TARTIŞMA}

Bu çalışmada, sismik tekstil malzemesi ile güçlendirilen tuğla ve bims duvar numunelerinin üç noktalı kesme deneyleri ile mekanik davranışları incelenmiştir. Ayrıca güçlendirme işlemine tabi tutulmadan ele alınan numunelerle karşılaştırmalar yapılarak, ülkemizdeki mühendislik hizmeti almamış ve kültürel mirasımızın önemli ögeleri olan yığma yapı stoğunun olası depremleri minimum hasarla atlatabilmesi için güçlendirmenin önemine odaklanmaya çalışılmıştır. Elde edilen bilgiler 1şı̆̆ında, alkali dirençli cam ve polipropilen esaslı kompozit malzemenin süneklik kapasitesini önemli ölçüde arttırdığı tespit edilmiştir. Söz konusu malzemenin numune yüzeyine tatbik edilmesini sağlayan cam kürecik esaslı yapıştırma sıvası da enerji yutma kapasitesi üzerinde etkilidir. Referans numunelerde yapılan deneyler bimsin süneklik kapasitesinin tuğladan daha yüksek olduğunu göstermiştir.

\section{KAYNAKÇA}

[1] Wallner C. Erdbebengerechtes verstärken von mauerwerk durch faserverbundwerkstoffe experimentelle und numerische untersuchungen. Ph. D. Thesis. Karlsruhe Institute of Technology, Karlsruhe, Germany, 2008.

[2] Oliveira DVC. Experimental and numerical analysis of blocky masonry structures under cyclic loading. Ph. D Thesis. University of Minho, Portugal, 2003.

[3] Lourenço PB, Barros JO, Oliveira JT. Shear testing of stack bonded masonry. Construction and Building Materials 2004; 18:125-132.

[4] EN 1052-3, European norms for methods of test for masonry-Part 3: Determination of initial shear strength; 1996.

[5] İstegün B. Kompozit sismik kumaş ile güçlendirilmiş taşıyıcı duvar elemanlarının üç noktalı kesme deneyleri ile performanslarının değerlendirilmesi. Yüksek Lisans Tezi. Sakarya Üniversitesi, Fen Bilimleri Enstitüsü, İnşaat Mühendisliği Bölümü, 2018.

6] Papanicolaou CG, Triantafillou TC, Karlos K, Papathanasiou M. Textile-reinforced mortar (TRM) versus FRP as strengthening material of URM walls: in-plane cyclic loading. Materials and Structures 2007; 40(10): 1081-1097. [7] Rizzo S. Triplet shear tests on pumice blocks BLG19 with and without the seismic retrofitting system Röfix SismaCalce. Final Report. Department Reinforced Concrete, Karlsruhe Institute of Technology, Karlsruhe, Germany, 2015. 